Review began 11/09/2021 Review ended 01/09/2022 Published 01/13/2022

๑) Copyright 2022

Patro et al. This is an open access article distributed under the terms of the Creative Commons Attribution License CC-BY 4.0. which permits unrestricted use, distribution, and reproduction in any medium, provided the original author and source are credited.

\section{Cost of Ambulatory Care in Diabetes: Findings From a Non-Communicable Disease Clinic of a Tertiary Care Institute in Eastern India}

\author{
Binod K. Patro ${ }^{1}$, Manish Taywade ${ }^{1}$, Debjyoti Mohapatra ${ }^{2}$, Rashmi R. Mohanty ${ }^{3}$, Kishore K. Behera ${ }^{4}$, \\ Soumya S. Sahoo ${ }^{5}$ \\ 1. Community Medicine and Family Medicine, All India Institute of Medical Sciences, Bhubaneswar, Bhubaneswar, IND \\ 2. Community Medicine, Srirama Chandra Bhanja Medical College, Cuttack, IND 3. General Medicine, All India \\ Institute of Medical Sciences, Bhubaneswar, Bhubaneswar, IND 4. Endocrinology, All India Institute of Medical \\ Sciences, Bhubaneswar, Bhubaneswar, IND 5. Community and Family Medicine, All India Institute of Medical Sciences, \\ Bathinda, Bathinda, IND
}

Corresponding author: Soumya S. Sahoo, swaroop.drsoumya@gmail.com

\begin{abstract}
Background: This study was conducted to evaluate the cost of ambulatory care of diabetes in a noncommunicable disease (NCD) clinic in eastern India.

Methods: This hospital-based cross-sectional cost description study was conducted from July to August 2018. A total of 192 diagnosed cases aged 18-70 years with a minimum history of one year since diagnosis attending the NCD clinic for the first time were included. Information was collected using a pre-tested schedule based on the cost of illness approach that consisted of socio-demographic details, disease status, and cost of ambulatory care. Cost of the drugs was calculated using a standardized repository of drug costs. The estimated expenditure of previous three months was calculated and extrapolated to one year to calculate yearly expenditure.
\end{abstract}

Results: The mean age of the study participants was $43.93 \pm 10.41$ years and the mean duration of diabetes was $6.64 \pm 6.08$ years. The median direct cost due to diabetes was Rs 9560 (136.57 USD) annually. It was higher in females (Rs 10,056, 143.45 USD) than in males (Rs 9020, 128.85 USD). In direct medical costs, a major part was constituted by the drugs, oral hypoglycemic agents, and/or insulin (approximately 70\%).

Conclusions: In an ambulatory framework too, diabetes causes a substantial financial burden on the individual in India. In the wake of resource constraints in Indian health settings, the public health system needs to be adequately strengthened by policymakers to address the growing number of diabetics and longstanding complications.

Categories: Endocrinology/Diabetes/Metabolism, Family/General Practice, Epidemiology/Public Health Keywords: india, ambulatory care, cost of illness, primary care, diabetes

\section{Introduction}

India is experiencing a growing burden of non-communicable diseases (NCDs). The disease landscape has vastly transitioned from infectious diseases to a predominantly chronic NCD pattern. Unfortunately, the pace of growth of NCDs in India has been alarmingly high. They contribute to around 41 million (70\%) of all the deaths globally and about 5.81 million (61\%) of all deaths in India [1]. Four NCDs primarily responsible for mortality and morbidity are cardiovascular diseases, chronic respiratory disease, cancers, and diabetes, contributing to about $82 \%$ of all NCD deaths [2]. India is regarded as the diabetes capital of the world, entirely because of the number of rising new cases and a large burden of old prevalent cases. The Indian Council of Medical Research-India Diabetes (ICMR- INDIAB) study in 15 states of India showed the overall prevalence of diabetes to be 7.3\% [3]. The Global Burden of Disease (GBD) 2016 study reported diabetes contributes $3.1 \%$ (95\% CI 2.9-3.3) of the total mortality burden, with slightly higher contributions among women than men. The age-standardized diabetes prevalence rose by $29.7 \%$ from 1990 to 2016 [4]. In absolute numbers, the prevalence of diabetes is projected to increase to 80 million by 2030, placing an immense burden on healthcare resources [5].

Exacerbating this problem are the accompanying multiple chronic conditions and the fact that many remain undiagnosed, due to lack of awareness and insufficient healthcare access [6]. These diseases because of their chronic nature and high burden of morbidity need a long-term continuum of care. Though there has been a significant increase in the burden of diabetes and other NCDs in recent times, there is a lack of integration of primary healthcare with the programmatic implementation of NCD management in India. Diabetes, being a long-standing disease with complications, makes it challenging for the underprepared health systems to deal with the frequent and intensive encounters with the disease [7]. Along with the long course of the 
disease, the financial implications of the frequent costs, consultations, medications, and different indirect costs put a significant economic burden on the people. The Lancet global cost of illness study for diabetes estimated that the global cost of diabetes for 2015 was 1.31 trillion USD or $1.8 \%$ of the global gross domestic product (GDP). It also highlighted the substantial variations in the share and composition of indirect costs across countries [8]. There has been scarce literature on studies regarding the comprehensive cost of diabetes from developing countries, with relatively few of them being from India. In this context, as most of the patients with diabetes are treated as outpatients, we conducted this ambulatory cost of care for diabetes study in an NCD clinic of a tertiary care institute in eastern India.

\section{Materials And Methods}

\section{Study setting}

This cross-sectional cost description study was conducted in the NCD clinic of a tertiary care center of eastern India that caters to the needs of entire Odisha and neighboring states like West Bengal. The NCD clinic is managed by community medicine physicians with a daily attendance of about 50 patients. The recruitment of study participants and data collection was done over a period of three months from June to August 2018. A total of 192 type 2 diabetic subjects were included in the study. All diagnosed cases of diabetes mellitus with a minimum history of six months since diagnosis and with age greater than 18 years attending the NCD clinic, of All India Institute of Medical Sciences, Bhubaneswar, for the first time were eligible for inclusion.

\section{Study methodology and tool}

Patients attending the NCD clinic were screened by the Senior Resident/Faculty of Community Medicine for eligibility. The maximum number of subjects to be enrolled in a day was limited to five to maintain the quality of data. Subjects found eligible were sent to the study station situated in the NCD clinic where they were interviewed by a trained person (medical social worker) (Figure 1). Data was collected using a pretested schedule based on the cost of illness approach that consisted of the following sections: (a) socioeconomic and demographic detail of participants, (b) details of their disease status, (c) health-seeking behavior in the past three months, and (d) cost of ambulatory care in diabetes management including direct medical and non-medical costs. 


\section{Cureus}

Fig 1:

FLOW CHART OF METHODOLOGY

Central registration of patients

NCD Prevention Clinic

Screening of known diabetic cases as per inclusion and exclusion criteria

Inclusion criteria

1. Known diabetic case attending AIIMS Bhubaneswar for first time

2. Minimum duration of disease diagnosis of at least 6 months

\footnotetext{
C

Eligible candidates sent to study station located in NCD Prevention Clinic.

All eligible candidates given advice on lifestyle modification and suitable treatment

A maximum of five patients per day.

Anthropometric measurements and interview of the selected candidate to calculate cost of ambulatory care in diabetes in INR (USD\$).
}

\section{FIGURE 1: Flowchart of the methodology process}

NCD, non-communicable disease; AlIMS, All India Institute of Medical Sciences; DM, diabetes mellitus; INR, Indian rupee

Direct medical cost captured the cost of drugs related to diabetes and complications related to diabetes (hypertension, coronary artery disease, dyslipidemia, peripheral neuropathy, diabetic kidney disease, and diabetic retinopathy), cost of consultation, cost of investigation advised in relation to the disease, and cost of self-monitoring. Direct non-medical cost captured the data on the cost of transportation and cost of food. To keep recall bias to a minimum, only the expenditure incurred in the past three months was taken into account. The patients were asked to show the drugs taken during the past three months or their prescription. In case patients could not recall or produce the drugs or past prescriptions during the personal interview, they were asked by the interviewer to confirm the same telephonically once they returned home. Wherever possible, the image of the drug packets was shared with the interviewer using messaging apps. The cost of the drugs was calculated using a standardized repository of drug costs for medical cost and as per the existing prices on the day of data collection. The estimated expenditure of the previous three months was calculated and was extrapolated to one year to calculate the patient's estimated yearly expenditure.

Data were entered into MS Excel and analysed using IBM SPSS Statistics for Windows, Version 20.0 (IBM Corp., Armonk, NY). The median cost of ambulatory care was expressed as annual cost in Indian rupees. The study was approved by the Institutional Ethics Committee of All India Institute of Medical Sciences, Bhubaneswar. 


\section{Cureus}

\section{Results}

\section{Socio-demographic profile}

A total of 192 diabetic patients were included in our study. Out of them, more than two-thirds, $66.1 \%$ $(\mathrm{n}=127)$, were males and a majority $(78.1 \%)$ of the study participants were in the 30-59 age group. The mean age of the study participants was $43.93 \pm 10.41$ years and the mean duration of diabetes was $6.64 \pm 6.08$ years. The majority, 132 (68.8\%), of them were residing in rural areas and nearly one-fifth, 38 (18.7\%), of the study participants were unemployed or retired. Nearly one-third, 57 (29.7\%), of them belonged to the below poverty line category (Table 1$)$. The mean age at diagnosis was marginally higher in males $(44.57 \pm 10.92$ years) than females $(43.51 \pm 9.59$ years $)$.

\section{Characteristic}

Gender

Male

Female

Age (years)

$<30$

$30-59$

$\geq 60$

Education

Illiterate

Primary

Secondary

Middle

Matriculate

Graduate and above

Residence

Rural

Urban

$60(30.8)$

Current marital status

Married

Unmarried

Widower

Separated

Occupation

Unemployed

Homemaker

Govt service

Business/Self-employed

Semi/Unskilled

Retired

Monthly family income

APL
135 (70.3) 


\section{Cureus}

BPL 57 (29.7)

Social group

General

Other backward class

Schedule caste/schedule tribe

$25(13.0)$

\section{TABLE 1: Socio-demographic characteristic of participants}

$\mathrm{APL}$, above poverty line; BPL, below poverty line

\section{Care-seeking behavior}

In the majority, 139 (72.4\%), of patients, the health-seeking behavior for diabetes was self-initiated, when they first experienced the symptoms and were subsequently diagnosed. More than half of the participants had their first diagnosis in the private sector (private practitioner, nursing home, and hospitals). Three study subjects admitted to being diagnosed by a traditional faith healer/quack. However, in the last three months, more than half were seeking care/having checkups in government institutions. In terms of the consulting doctors, nearly half (51.2\%) of the study subjects sought care from a general physician whereas about one-third (31.8\%) of them sought care from either a specialist or super-specialist. Most (148, 77.1\%) of the patients were on oral hypoglycemic agents (OHAs) while some of them were on insulin and OHAs both. It was worrying to see that $16(8.3 \%)$ patients had not taken any medicines in the previous three months. Two-thirds of the patients had some form of long-term complications at the time of enrollment, microvascular or macrovascular or both. Hypertension was the most common associated co-morbidity. It was quite encouraging to see that nearly half of the patients had no co-morbidities associated (Table 2).

\begin{tabular}{|c|c|c|c|}
\hline & Male $(n=127)(\%)$ & Female $(n=65)(\%)$ & Total $(n=192)(\%)$ \\
\hline Age at first diagnosis (years) & $44.57 \pm 10.92$ & $43.51 \pm 9.59$ & $43.93 \pm 10.41$ \\
\hline Duration of diabetes (years); median (IQR) & $4(8)$ & $3(5)$ & $4(7)$ \\
\hline \multicolumn{4}{|l|}{ Initiation of first diagnosis } \\
\hline Self-initiated & $95(74.8)$ & $44(67.7)$ & $139(72.4)$ \\
\hline Opportunistic/incidental & $31(24.4)$ & $23(30.8)$ & 55 (26.6) \\
\hline Others & $1(0.8)$ & $1(1.5)$ & $2(1.0)$ \\
\hline \multicolumn{4}{|l|}{ Place of diagnosis } \\
\hline Govt health facility & $31(24.4)$ & $21(32.3)$ & $52(27.1)$ \\
\hline Private practitioner & $54(42.5)$ & $25(38.5)$ & $83(41.1)$ \\
\hline Polyclinic & $14(11.0)$ & $5(7.7)$ & $19(9.9)$ \\
\hline Corporate hospitals & $7(5.5)$ & $3(4.6)$ & $10(5.2)$ \\
\hline Medical college & $19(15.0)$ & $10(15.4)$ & $29(15.1)$ \\
\hline Quack/traditional faith healer & $2(1.6)$ & $1(1.5)$ & $3(1.6)$ \\
\hline \multicolumn{4}{|l|}{ Place of care in the last three months } \\
\hline Govt health facility (PHC, CHC, DH) & $45(34.1)$ & $22(34.3)$ & $67(34.2)$ \\
\hline Private practitioner & $25(19.4)$ & $22(33.8)$ & $46(24.5)$ \\
\hline Polyclinics & $8(6.3)$ & $2(3.1)$ & $10(5.2)$ \\
\hline Corporate hospitals & $6(4.7)$ & $1(1.5)$ & $7(3.6)$ \\
\hline Medical college & $18(14.2)$ & $8(12.3)$ & $26(13.5)$ \\
\hline Quack/traditional faith healer & $5(3.9)$ & $2(3.1)$ & $7(3.6)$ \\
\hline Dual consultation & $1(0.8)$ & 1 (1.5) & $2(1.0)$ \\
\hline
\end{tabular}




\section{Cureus}

\begin{tabular}{|c|c|c|c|}
\hline No consultation & $19(15.0)$ & $7(10.8)$ & $28(13.5)$ \\
\hline \multicolumn{4}{|l|}{ Primary treating physician in the last three months } \\
\hline General physician & $65(51.2)$ & $27(41.5)$ & $92(47.9)$ \\
\hline Specialist & $29(22.8)$ & $24(36.9)$ & $53(27.6)$ \\
\hline Super-specialist & $6(4.7)$ & $2(3.0)$ & $8(4.2)$ \\
\hline Alternative system of medicine & $7(5.5)$ & $4(6.2)$ & $11(5.7)$ \\
\hline Consulted two different grades of physician & $1(0.8)$ & $1(1.5)$ & $2(1.0)$ \\
\hline Did not seek care & $19(14.7)$ & $7(10.8)$ & $26(13.5)$ \\
\hline \multicolumn{4}{|l|}{ Medicines in the past three months } \\
\hline $\mathrm{OHA}$ & $97(75.2)$ & $51(78.5)$ & $148(77.1)$ \\
\hline Insulin & $6(6.2)$ & $0(1.5)$ & $6(3.1)$ \\
\hline Insulin and $\mathrm{OHA}$ & $12(9.4)$ & $6(9.2)$ & $18(9.4)$ \\
\hline Alternative system of medicine & $2(1.6)$ & $2(3.1)$ & $4(2.1)$ \\
\hline None & $10(7.9)$ & $6(9.2)$ & $16(8.3)$ \\
\hline \multicolumn{4}{|l|}{ Place from where medicine was taken } \\
\hline Govt supply & $9(7.1)$ & $5(7.7)$ & $14(7.3)$ \\
\hline Chemist shop & $106(83.5)$ & $53(81.5)$ & $159(82.8)$ \\
\hline Both govt supply and chemist shop & $2(1.6)$ & $1(1.5)$ & $3(1.6)$ \\
\hline Not taken medicine in the past three months & $10(7.9)$ & $6(9.2)$ & $16(8.3)$ \\
\hline \multicolumn{4}{|l|}{ Complication } \\
\hline Microvascular & $60(47.2)$ & $33(50.8)$ & $93(48.4)$ \\
\hline Macrovascular & $7(5.5)$ & $2(3.1)$ & $7(3.6)$ \\
\hline Both & $8(6.3)$ & $5(7.7)$ & $13(6.8)$ \\
\hline None & $53(40.9)$ & $25(38.5)$ & $77(40.1)$ \\
\hline \multicolumn{4}{|l|}{ Co-morbidity } \\
\hline Hypertension & $40(31.5)$ & $20(30.8)$ & $60(31.2)$ \\
\hline CAD & $2(1.6)$ & $0(0)$ & $2(1.0)$ \\
\hline TB & $1(0.8)$ & $0(0)$ & $1(1.0)$ \\
\hline COPD & $3(2.4)$ & $1(1.5)$ & $4(2.1)$ \\
\hline Thyroid disorder & $3(2.4)$ & $3(4.6)$ & $6(3.1)$ \\
\hline Others & $4(3.1)$ & $0(0)$ & $4(2.1)$ \\
\hline Two co-morbidities & $4(3.1)$ & $2(3.1)$ & $6(3.1)$ \\
\hline More than 2 co-morbidities & $2(1.6)$ & $0(0)$ & $2(1.0)$ \\
\hline None & $67(52.8)$ & $31(47.7)$ & $98(51.0$ \\
\hline
\end{tabular}

\section{TABLE 2: Details of diabetes among study participants}

IQR, interquartile range; $\mathrm{PHC}$, primary health center; $\mathrm{CHC}$, community health center; $\mathrm{DH}$, district hospital; OHA, oral hypoglycemic agent; CAD, coronary artery disease; TB, tuberculosis; COPD, chronic obstructive pulmonary disease

\section{Cost of diabetes care}




\section{Cureus}

The median direct cost due to diabetes was Rs 9560 (136.57 USD) annually. The median total direct cost was found to be higher in females (Rs 10,056, 143.45 USD) than in males (Rs 9020, 128.85 USD). The direct medical costs due to diabetes alone in three months were Rs 1520 (873-1728). When the cost of drugs for complications and co-morbidities were included, the total cost was marginally higher at Rs 1931 (933-3244) in the past three months (Table 3). In this case too, gender-wise the cost was higher in females as compared to males. In the direct medical costs, the major part was constituted of the drugs, OHA and/or insulin (approximately 70\%). The costs of consultation, investigation, and self-monitoring constituted only a fractional cost of the total direct cost. The direct non-medical cost, which included transport cost and food costs mainly, was also minimal.

\begin{tabular}{|c|c|c|c|}
\hline & $\begin{array}{l}\text { Total (in rupees); } \\
\text { median (IQR) }\end{array}$ & $\begin{array}{l}\text { Cost in males ( } n=127) \text { (In } \\
\text { rupees); median (IQR) }\end{array}$ & $\begin{array}{l}\text { Cost in females }(n=65) \text { (In } \\
\text { rupees); median (IQR) }\end{array}$ \\
\hline \multicolumn{4}{|l|}{ Direct medical cost } \\
\hline OHA and/or Insulin & $1059(576-1955)$ & $1000(571-1565.5)$ & $1126(637.5-2407.5)$ \\
\hline Cost of consultation & $0(0-400)$ & $0(0-300)$ & $0(0-350)$ \\
\hline Cost of investigation & $160(0-300)$ & $120(0-280)$ & $160(0-300)$ \\
\hline Cost of self-monitoring & $0(0-300)$ & $0(0-0)$ & $0(0-0)$ \\
\hline $\begin{array}{l}\text { Total direct medical cost (without } \\
\text { complications) }\end{array}$ & $1520(873-1728)$ & 1471 (844.5-2682.0) & $1717.5(937-3232)$ \\
\hline $\begin{array}{l}\text { Total direct medical cost (with } \\
\text { complications and co-morbidities) }\end{array}$ & 1931 (933-3244) & 1914 (920-2978) & 2134 (964.2-3668.5) \\
\hline \multicolumn{4}{|l|}{ Direct non-medical cost } \\
\hline Transport cost & $100(0-300)$ & $90(0-200)$ & $70(0-350)$ \\
\hline Food cost & $40(40-150)$ & $25(0-110)$ & $10(0-120)$ \\
\hline lotal direct non-medical cost & $120(0-330)$ & $140(10-300)$ & $117.5(0-392.5)$ \\
\hline $\begin{array}{l}\text { Total direct cost (medical and non- } \\
\text { medical) }\end{array}$ & $2390(1096-3664)$ & 2255 (1140.5-3415) & $2514(1022.2-4025.5)$ \\
\hline Total direct cost annually & 9560 (136.57 USD) & 9020 (128.85 USD) & 10,056 (143.65 USD) \\
\hline
\end{tabular}

\section{TABLE 3: Median cost of diabetes care distribution according to gender}

$\mathrm{OHA}$, oral hypoglycemic agent; IQR, interquartile range

\section{Discussion}

Care of diabetes is a challenge in many aspects in a developing country like India. The economic implications of diabetes need to be studied upon in view of the clinical, health system, and societal implications. First and foremost, the private healthcare sector is the major provider of diabetes care in India, and being a chronic disease, it has large repercussions on out-of-pocket (OOP) expenditure [9]. Secondly, by 2025 most diabetics would be in the 45 - to 64 -year age group threatening the economic productivity of the country and earning ability of individuals [10].

The highest economic burden caused by diabetes is the monetary value associated with disability and loss of life as a result of the disease itself and related chronic complications. Also, it is not surprising that within diabetic patients, the greatest financial burden is borne by the poorest quintile. The median private sector OOP hospitalization expenditure is four times higher than the public sector $(p<0.001)$ [11]. In our study, among the direct costs, the cost of medicine (OHA and/or insulin) formed the bulk. This has been the case in many other studies in India [6,12-14]. However, the Cost of Diabetes in India (CODI) study outlined that anti-diabetic drug costs accounted only for $17 \%$ of direct medical expenses on diabetes care [15]. A secondary National Sample Survey Organization (NSSO) data analysis by Tripathy and Prasad reported medicines accounted for $69 \%$ of public sector outpatient care [11]. In our study, this may be attributed to the fact that a large majority of patients were buying the medications from chemist shops/private vendors. The chronic nature of the disease along with the daily need for medicines puts a great burden on the patients. This is exacerbated in patients on insulin and particularly in patients with uncontrolled diabetes. This makes the need for ensuring the essential anti-diabetic drugs in the public sector all the more important. 
Also, the increased sensitization of patients to Jan Aushadhi stores and other similar subsidized ventures can significantly reduce this financial burden. The poor availability and affordability of essential diabetes medicines in many communities, especially those from low and middle-income countries (LMIC) like India, does not help the cause [16]. The Global Action Plan for the Prevention and Control of Noncommunicable Diseases 2013-2020 sets a voluntary target of 80\% availability of affordable essential medicines, required to treat major NCDs in both public and private facilities by 2025 [17].

The median cost in rupees for consultation and self-monitoring was negligible. This can be because of relatively stable patients and most of the patients requiring simple blood tests like fasting and postprandial that do not cost much. Alternatively, this may be due to poor self-monitoring practices and inadequate health-seeking behavior with less frequent visits for consultation. The direct non-medical costs due to transportation and food were also minimal as most of the patients came from nearby localities making the visits equivalent to daycare.

The median direct cost due to diabetes was Rs 9560 (USD 136.57) annually that was lower as estimated in comparison to some studies. A systematic review on cost of illness studies in LMIC outlined a clear trend of increment in the average annual direct cost per person per year, from USD 106.53 in 1997 purchasing power parity, to USD 293.79 in 2012 [18]. The difference in expenditure could be due to different approaches in the methodology of calculating costs, duration of illness for which the cost was estimated, severity, and type of the disease. The time frame of the studies conducted, periodic variations due to inflation, and healthcare utilization at different levels of the health system limit the extension of comparison. However, considering the average annual per capita income of households as Rs 44,901, according to the Longitudinal Aging Study in India, 2017-18, the direct costs calculated in our study are nearly one-fifth of the annual income [19]. This shows that healthcare costs in this context are still quite unaffordable.

However, the findings of the present study and other studies over India unequivocally underline the fact that costs of diabetes care are exorbitant with a higher economic burden, particularly on the poor. Health system interventions are needed to tackle this keeping in view the increase in the absolute number of diabetics and long-term complications. Universal health coverage with increased accessibility and affordable care can be helpful in ameliorating this problem. Additionally, preventive approaches need to be stressed upon for adequate control of the disease and long-term complications. Screening, early disease detection, and initiation of treatment will be some of the most cost-effective strategies for countering diabetes [20-22]. Also, there should be an emphasis on the aspects of prevention and patient health education, along with a focus on health literacy.

India being a resource-limited setting needs efficient utilization of resources along with community-based preventive approaches to manage the disease effectively. The primary care system, particularly primary health centers, can be the major player in reducing the escalating costs of diabetes care by providing adequate access to drugs, investigation, and laboratory facilities. Strengthening the public health system with a focus on primary care and the expansion of the health coverage blanket are the potential solutions subsequent to the diabetes epidemic.

The present study has some limitations. Patient-reported data are likely to be influenced by recall bias. Efforts were made on the part of interviewers to minimize the errors by adhering to a standardized pattern of interviews and using appropriate probes to maintain data accuracy. Inpatient costs, if any, were not included in the study though very few of the patients reported having been admitted in the last year. It also did not take into account the health system perspective of costs. The compliance and control status of the study participants was also not assessed. However, our study has generalizability in the context of ambulatory care, where patients are buying medicines mostly from private chemists or some subsidized public sector undertaking. In the context of public health facilities where the medications are available free of cost, the costs might be lower. Nevertheless, to our knowledge, this is the first cost of illness study from eastern India on diabetes. It would help in developing comprehensive knowledge on economic implications of the disease and would also help from a policy formulation point of view.

\section{Conclusions}

The study outlines that cost of diabetes treatment is a significant financial burden in a developing country like India, even in an ambulatory framework. Given the resource constraints in Indian health settings, the public health system needs to be adequately strengthened by policymakers to address the ever-increasing number of diabetics and long-standing complications. Increased availability and access to essential antidiabetic drugs will lead to better management and reduce out-of-pocket expenditure in public sector facilities.

\section{Additional Information \\ Disclosures}

Human subjects: Consent was obtained or waived by all participants in this study. All India Institute of Medical Sciences, Bhubaneswar issued approval IEC/IM-NF/CM\&FM/18. Animal subjects: All authors have 
confirmed that this study did not involve animal subjects or tissue. Conflicts of interest: In compliance with the ICMJE uniform disclosure form, all authors declare the following: Payment/services info: All authors have declared that no financial support was received from any organization for the submitted work. Financial relationships: All authors have declared that they have no financial relationships at present or within the previous three years with any organizations that might have an interest in the submitted work. Other relationships: All authors have declared that there are no other relationships or activities that could appear to have influenced the submitted work.

\section{References}

1. Dandona L, Dandona R, Kumar GA, et al.: Nations within a nation: variations in epidemiological transition across the states of India, 1990-2016 in the Global Burden of Disease Study. Lancet. 2017, 390:2437-60. 10.1016/S0140-6736(17)32804-0

2. Department for Prevention of Noncommunicable Diseases, World Health Organization: Noncommunicable Diseases Progress Monitor 2017. World Health Organization, Geneva; 2017.

3. Anjana RM, Deepa M, Pradeepa R, et al.: Prevalence of diabetes and prediabetes in 15 states of India: results from the ICMR-INDIAB population-based cross-sectional study. Lancet Diabetes Endocrinol. 2017, 5:58596. 10.1016/s2213-8587(17)30174-2

4. Tandon N, Anjana RM, Mohan V, et al.: The increasing burden of diabetes and variations among the states of India: the Global Burden of Disease Study 1990-2016. Lancet Glob Health. 2018, 6:E1352-62. 10.1016/S2214-109X(18)30387-5

5. Aswathy S, Unnikrishnan AG, Kalra S: Effective management of type $2 \mathrm{DM}$ in India: looking at low-cost adjunctive therapy. Indian J Endocrinol Metab. 2013, 17:149-52.

6. Arokiasamy P: India's escalating burden of non-communicable diseases. Lancet. 2018, 6:E1262-3. 10.1016/S2214-109X(18)30448-0

7. Grover S, Avasthi A, Bhansali A, Chakrabarti S, Kulhara P: Cost of ambulatory care of diabetes mellitus: a study from north India. Postgrad Med J. 2005, 81:391-5. 10.1136/pgmj.2004.024299

8. Bommer C, Heesemann E, Sagalova V, Manne-Goehler J, Atun R, Bärnighausen T, Vollmer S: The global economic burden of diabetes in adults aged 20-79 years: a cost-of-illness study. Lancet Diabetes Endocrinol. 2017, 5:423-30. 10.1016/S2213-8587(17)30097-9

9. Singla R, Bindra J, Singla A, Gupta Y, Kalra S: Drug prescription patterns and cost analysis of diabetes therapy in India: audit of an endocrine practice. Indian J Endocr Metab. 2019, 23:40-5.

10. Diabetes mellitus. (2020). Accessed: January 20, 2020: http://www.who.int/mediacentre/factsheets/fs312/en/.

11. Tripathy JP, Prasad BM: Cost of diabetic care in India: an inequitable picture . Diabetes Metab Syndr. 2018, 12:251-5. 10.1016/i.dsx.2017.11.007

12. Kumar A, Nagpal J, Bhartia A: Direct cost of ambulatory care of type 2 diabetes in the middle and high income group populace of Delhi: the DEDICOM survey. J Assoc Physicians India. 2008, 56:667-74.

13. Ramachandran A, Ramachandran S, Snehalatha C, et al.: Increasing expenditure on health care incurred by diabetic subjects in a developing country: a study from India. Diabetes Care. 2007, 30:252-6. 10.2337/dc060144

14. Tharkar S, Devarajan A, Kumpatla S, Viswanathan V: The socioeconomics of diabetes from a developing country: a population based cost of illness study. Diabetes Res Clin Pract. 2010, 89:334-40. 10.1016/j.diabres.2010.05.009

15. Kapur A: Economic analysis of diabetes care. Indian J Med Res. 2007, 125:473-82.

16. Chow CK, Ramasundarahettige $\mathrm{C}, \mathrm{Hu}$ W, et al.: Availability and affordability of essential medicines for diabetes across high-income, middle-income, and low-income countries: a prospective epidemiological study. Lancet Diabetes Endocrinol. 2018, 6:798-808. 10.1016/S2213-8587(18)30233-X

17. World Health Organization: Global Action Plan for the Prevention and Control of Noncommunicable Diseases 2013-2020. World Health Organization, Geneva; 2013. https://apps.who.int/iris/handle/10665/94384.

18. Afroz A, Alramadan MJ, Hossain MN, Romero L, Alam K, Magliano DJ, Billah B: Cost-of-illness of type 2 diabetes mellitus in low and lower-middle income countries: a systematic review. BMC Health Serv Res. 2018, 18:972. 10.1186/s12913-018-3772-8

19. Longitudinal Ageing Study in India (LASI), 2017-18 . (2020). Accessed: January 13, 2022: https://lasi.hsph.harvard.edu/files/lasi/files/lasi_india_report_2020.pdf?m=1610054498.

20. Kahn R, Alperin P, Eddy D, et al.: Age at initiation and frequency of screening to detect type 2 diabetes: a cost-effectiveness analysis. Lancet. 2010, 17:1365-74. 10.1016/S0140-6736(09)62162-0

21. Diabetes Prevention Program Research Group: Within-trial cost-effectiveness of lifestyle intervention or metformin for the primary prevention of type 2 diabetes. Diabetes Care. 2003, 26:2518-23. 10.2337/diacare.26.9.2518

22. Ramachandran A, Snehalatha C, Yamuna A, Mary S, Ping Z: Cost-effectiveness of the interventions in the primary prevention of diabetes among Asian Indians: within-trial results of the Indian Diabetes Prevention Programme (IDPP). Diabetes Care. 2007, 30:2548-52. 10.2337/dc07-0150 